\title{
Emotion recognition in pictures of facial affect: Is there a difference between forensic and non-forensic patients with schizophrenia?
}

\author{
Wiebke Wolfkühler,,** \\ Karina Majorek*,** \\ Cumhur Tas ${ }^{\star, \star *}$ \\ Christian Küper*** \\ Nahlah Saimeh ${ }^{\star \star \star *}$ \\ Georg Juckel* \\ Martin Brüne ${ }^{\star, \star *}$ \\ * Department of Psychiatry, University \\ of Bochum, LWL University Hospital \\ ** Research Department of Cognitive
} Neuropsychiatry and Psychiatric Preventive Medicine, University of Bochum, LWL University Hospital

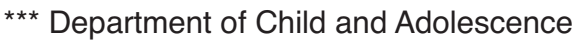
Psychiatry, Bertha Hospital Oberhausen

**** Department of Forensic Psychiatry, LWL Hospital Lippstadt

GERMANY

\footnotetext{
ABSTRACT - Background and Objectives: Abundant research has demonstrated that patients with schizophrenia have difficulties in recognizing the emotional content in facial expressions. However, there is a paucity of studies on emotion recognition in schizophrenia patients with a history of violent behavior compared to patients without a criminal record.

Methods: Emotion recognition skills were examined in thirty-three forensic patients with schizophrenia. In addition, executive function and psychopathology was assessed. Results were compared to a group of 38 schizophrenia patients in regular psychiatric care and to a healthy control group.

Results: Both patient groups performed more poorly on almost all tasks compared to controls. However, in the forensic group the recognition of the expression of disgust was preserved. When the excitement factor of the Positive and Negative Syndrome Scale was co-varied out, forensic patients outperformed the non-forensic patient group on emotion recognition across modalities.

Conclusions: The superior recognition of disgust could be uniquely associated with delinquent behavior.
} 


\section{Introduction}

Emotion recognition from facial expressions is a cornerstone of social interaction ${ }^{1,2}$. The ability to decipher emotions in faces is universal across cultures, especially when focusing on the basic emotions of happiness, anger, disgust, sadness, fear, surprise and contempt ${ }^{3}$. Impairment in recognizing facial expressions of emotion is characteristic of schizophrenia ${ }^{4-7}$. Poor emotion recognition in schizophrenia has been found to be associated with poor social functioning ${ }^{8-10}$. There is still contest about the question, however, whether poor emotion recognition in schizophrenia is more profound for negative emotions such as fear, anger, sadness, and disgust ${ }^{1,6,11,12}$, or whether patients with schizophrenia exhibit a more global deficit in emotion recognition ${ }^{13,14}$. Also, the question of whether or not the emotion recognition deficit in schizophrenia is limited to facial expressions ${ }^{15}$ or the consequence of a more generalized performance deficit ${ }^{16,17}$ remains to some extent elusive.

In any event, false interpretation of facial affect may lead to inappropriate social behavior, including impulsive aggression even in innocuous social situations ${ }^{18}$. Conversely, aggressive responses seem to be suppressed in healthy individuals when recognizing fear in others ${ }^{19}$. Consistent with this explanation, Hoaken et al. ${ }^{18}$ found that non-clinical violent offenders were significantly worse in facial affect recognition compared to non-violent offenders and controls, and that emotion recognition correlated with executive functioning abilities including associative learning, strategy formulation as well as working memory ${ }^{18}$.

In forensic samples diagnosed with schizophrenia, only a few studies have addressed emotion recognition abilities. Weiss et al. ${ }^{19}$ discovered in patients with either schizophrenia or schizoaffective disorder with a criminal record that emotion recognition impairments were associated with higher numbers of incarcerations ${ }^{19}$. Likewise, Fullam and Dolan $^{20}$ revealed impaired emotion recognition in male schizophrenia patients who also fulfilled the criteria for psychopathy ${ }^{20}$. The degree of impairment in recognising emotions in facial expressions was associated with the severity of psychopathy, particularly regarding fear and sadness. However, these studies have limited explanatory power due to a lack of a clinical control group.

Accordingly, in the present study we sought to investigate whether or not emotion recognition from facial expressions is impaired in forensic patients with schizophrenia compared to non-violent schizophrenic patients and a group of healthy controls. Moreover, we were interested in the question as to what extent emotion recognition was associated with executive functioning, and whether different patterns between the clinical groups emerged regarding the recognition of any specific expression of emotion.

\section{Methods}

\section{Participants}

Thirty patients (29 males, 1 female) diagnosed with schizophrenia according to ICD10 diagnostic criteria for research ${ }^{21}$, who were treated in a high security forensic psychiatric hospital, were examined. Findings were compared with a sample of 30 schizophrenia patients (18 males, 12 females) in a regular psychiatric hospital, diagnosed with schizophrenia according to ICD-10 diagnostic criteria for research, and with a group of 20 healthy controls ( 9 male, 11 female) 
recruited from students of psychology, their relatives, and hospital staff. Subjects with a history of traumatic brain injury or severe somatic disorders were excluded from the study. All participants gave full informed consent in writing after the procedure was fully explained and understood.

In the forensic group all but three patients (10\%) received antipsychotic medication, four patients $(13.3 \%)$ were treated with first-generation antipsychotics (FGA), another $11(36.7 \%)$ received second-generation antipsychotics (SGA), and 11 patients $(36.7 \%)$ received both FGA and SGA. In the non-forensic patient group, one patient $(3.3 \%)$ was on FGA, $24(80 \%)$ were treated with SGA, and five patients $(16.7 \%)$ received a combination of FGA and SGA.

Among the forensic patients, 25 patients $(83.3 \%)$ had a history of either drug or alcohol abuse, compared to 18 patients $(60 \%)$ in the non-forensic group. No history of drug or alcohol abuse was found in the healthy control group. The forensic patients' mean age at onset of the disorder was 22.2 years $(15-38$ years; $\mathrm{SD}=5.1$ yrs. $)$, and the mean duration of illness was 9.9 years $(1-28$ years; SD $=7.7 \mathrm{yrs}$.). The non-forensic patients' mean age at onset of the disorder was 23.8 years $(15-44$ years; $S D=6.6$ yrs. $)$, their mean duration of illness was 8.9 years (0-33 years; $\mathrm{SD}=8.6 \mathrm{yrs}$.). At the time of assessment, the forensic patients' mean age was 32.2 years (range $20-50$ years; $\mathrm{SD}=$ 7.3 yrs.), the non-forensic patients' mean age was 32.4 years (18-52 years; $\mathrm{SD}=9.3$ yrs.), and the healthy controls' mean age was 31.4 years ( $19-58$ years; $\mathrm{SD}=12.1 \mathrm{yrs}$.). The forensic group showed a heterogeneous pattern of criminal records, ranging from repetitive minor offenses (obstructing the police $(n=1)$, encroachment on traffic $(n=1)$, drink-driving $(\mathrm{n}=1)$ ) to capital crime (theft/ robbery $(n=9)$, arson $(n=3)$, coercion $(n=$
$1)$, criminal assault $(n=1)$, serial sexual offences $(n=4)$, severe bodily harm $(n=9)$, and manslaughter $(n=9))$.

\section{Emotion recognition tasks}

Emotion recognition was assessed using the "Japanese And Caucasian Brief Affect Recognition Test" 22 , comprising 56 photographs of facial expressions of seven universal emotions (i.e., anger, contempt, disgust, fear, happiness, sadness, and surprise) with an equal distribution of poser race (28 expressions each) and sex (28 expressions each) across emotions. Every item was composed of the emotional expression embedded in the same poser's neutral expression and presented for $200 \mathrm{~ms}$. Facial expressions were presented in randomized order. Participants were asked to name the respective emotion by clicking the allocated button on the computer screen using a standard PC mouse. To control for attention deficits, the same 56 photographs were shown expressing the neutral expression phase for $200 \mathrm{~ms}$ only. Participants were asked to indicate the gender of the presented face in the same way as they responded to the facial affect stimuli.

\section{Executive functioning tasks}

Cognitive flexibility was examined using a computerized and simplified version of the Wisconsin Card Sorting Test ${ }^{23}$. In addition, the first part of the Zoo Map Test taken from the Behavioral Assessment of the Dysexecutive Syndrome ${ }^{24}$ was used for testing executive planning skills.

\section{Psychopathology}

Psychopathology was measured using the Positive and Negative Syndrome Scale ${ }^{25}$. We 
used a five-factor structure for the PANSS comprising a negative, positive, excitement, cognitive and depression/anxiety component ${ }^{26}$. The patients' psychopathology was assessed blind to their performance on the executive functioning and emotion recognition tasks.

\section{Statistics}

For normally distributed variables, we used parametric tests including Bonferronicorrected ANOVAs for post-hoc comparisons between healthy controls and the two patient groups, as well as student's t-tests for comparisons between forensic and non-forensic patients. For non-normally distributed variables we used the appropriate nonparametric tests including Mann-Whitney- $U$ test for comparisons between the two patient groups and Kruskal-Wallis tests for comparisons between all three groups. Correlations were carried out using Pearson's correlation coefficient for normally distributed variables and Spearman's rho for non- normally distributed or interval-scaled variables. Statistical analysis was conducted using SPSS 16.0 for Windows.

\section{Results}

\section{Demographic variables and behavioral measures}

No differences between the groups were found with regard to age $(\mathrm{F}=0.67, \mathrm{df}=2, \mathrm{p}$ $=0.935)$. However, there was a significant difference between the groups in terms of gender distribution. In particular, males were over-represented in the forensic patient group (male to female ratio 29:1), compared to the non-forensic schizophrenia group (male to female ratio 18:12), and controls (male to female ratio 9:11). This difference was statistically significant (chi-square $=12.800, \mathrm{df}=1, \mathrm{p}<0.001)$. Both patient groups differed from controls regarding education, but not between each other (forensic vs. non-forensic: $\mathrm{t}=0.684 ; \mathrm{df}=58 ; p=$ 0.497; forensic vs. controls: Mann-Whitney-U $=182.000 ; Z=-2.445 ; p=0.014$; non-forensic vs. controls: Mann-Whitney-U $=161.000 ; \mathrm{Z}=-3.014 ; p=0.003)$. Also, as expected, both patient groups made more errors in the executive functioning tasks than controls (WCST: $p<0.001$; Zoo Map task $p=0.003)$, but did not differ between each other ( $p s=0.64$, and 1.0, respectively). Similarly, the amount of antipsychotic medication, as measured by the amount of chlorpromazine equivalents $(\mathrm{t}=1.363$; $\mathrm{df}=$ $42.421 ; p=0.180$ ) as well as the age at onset of the disorder $(\mathrm{t}=-1.016 ; \mathrm{df}=57 ; p=$ 0.314) did not differ between the two patient groups. However, forensic patients showed more frequently a history of drug or alcohol abuse than the non-forensic patients (Mann-Whitney-U = 345.000; $\mathrm{Z}=-1.989 ; p$ $=0.047)$. Demographic comparisons are summarized in Table 1.

Regarding psychopathology, no significant differences occurred between the two patient groups concerning positive symptoms $(\mathrm{t}=0.976 ; \mathrm{df}=57 ; \mathrm{p}=0.333)$ or negative symptoms $(\mathrm{t}=1.014 ; \mathrm{df}=51.016 ; \mathrm{p}=$ 0.315). However, forensic patients showed significantly more cognitive symptoms $(\mathrm{t}=$ 2.298 ; df $=56 ; \mathrm{p}=0.025)$ and excitementassociated symptoms $(\mathrm{t}=4.057 ; \mathrm{df}=57 ; \mathrm{p}=$ $<0.001)$ than non-forensic schizophrenia patients (summarized in Table 2). Conversely, non-forensic patients showed more depression and anxiety symptoms than forensic patients $(\mathrm{t}=-2.261 ; \mathrm{df}=57 ; \mathrm{p}=0.028)$. 
Table 1

Comparisons of demographic variables and executive functioning between forensic and non-forensic patients and healthy controls (with standard deviations)

Forensic Patients Non-Forensic Patients Control Group Significance level

\begin{tabular}{lcccl}
\hline Age & $32.2+/-7.3$ & $32.4+/-9.3$ & $31.4+/-12.1$ & $p=0.935$ \\
Male: Female Ratio & $29: 1$ & $18: 12$ & $9: 11$ & $p=<0.001$ \\
Education* & $11.5+/-1.9$ & $11.1+/-2.2$ & $12.6+/-1.3$ & $p=0.009$ \\
\hline
\end{tabular}

The item marked by an asterisk* was compared using non-parametric statistics.

Table 2

Comparison of demographic variables and psychopathology (with standard deviations) between forensic and non- forensic patient groups

\begin{tabular}{lccc} 
& Forensic & Non- Forensic & Significance \\
\hline Age (yrs.) & $32.2+/-7.3$ & $32.4+/-9.3$ & $p=0.926$ \\
Age at onset (yrs.) & $22.2+/-5.1$ & $23.8+/-6.6$ & $p=0.314$ \\
Duration of illness & $9.9+/-7.7$ & $8.9+/-8.6$ & $p=0.639$ \\
Chlorpromazine equivalents & $893.0+/-830.7$ & $655.1+/-431.8$ & $p=0.180$ \\
History of drug and alcohol abuse* & $25(83.3 \%)$ & $18(60 \%)$ & $p=0.047$ \\
PANSS positive component & $11.5+/-4.1$ & $10.4+/-4.6$ & $p=0.333$ \\
PANSS negative component & $18.4+/-4.8$ & $16.8+/-7.2$ & $p=0.315$ \\
PANSS excitement component & $10.2+/-2.3$ & $7.8+/-2.3$ & $p=<0.001$ \\
PANSS cognitive component & $13.3+/-3.6$ & $11.1+/-4.0$ & $p=0.025$ \\
PANSS depr. / anx. component & $10.5+/-2.6$ & $12.4+/-3.6$ & $p=0.028$ \\
\hline
\end{tabular}

Items marked by an asterisk* were compared using non-parametric statistics.

\section{Emotion recognition}

Both patient groups performed more poorly on most emotional displays than controls. Specifically, the non-forensic group was impaired, relative to controls, in the recognition of all seven basic emotions (all $p<0.05$ ), except sadness, where non-forensic patients did not differ significantly from controls $(\mathrm{MD}=-1.233 ; \mathrm{SE}=0.522 ; \mathrm{p}=0.062)$. The same was true for the forensic group (all $p<$ 0.05 ), except for disgust and fear where the forensic patients performed similar to controls (as regards disgust: $\mathrm{MD}=-0.700 ; \mathrm{SE}=$ $0.511 ; \mathrm{p}=0.523$; as regards fear: $\mathrm{MD}=$ 1.050; $\mathrm{SE}=0.529 ; \mathrm{p}=0.152$ ).
Concerning the comparison of emotion recognition between the two patient groups, no significant differences emerged in emotion recognition abilities (all $p>0.05$ ), except for disgust, where the forensic group outperformed the non-forensic patient group $(\mathrm{t}=3.225 ; \mathrm{df}=58 ; p=0.002)$. Notably, there was no difference between the patient groups and controls regarding sex recognition in either ethnicity (chi-square $=4.052, \mathrm{df}=2, \mathrm{p}$ $=0.132$ ).

Due to the significant differences regarding the participants' sex ratio we conducted ANCOVAs using sex as co-variate. However, no differences to the whole-group comparisons emerged, apart from the recogni- 
tion of the emotions of sadness and fear, where no difference between the controls and either one of the patient groups occurred. Thus, the mixed-gender groups were used for further comparisons.

Since the two patient groups differed with regard to the cognitive, the excitement and the depression and anxiety component of the PANSS, we conducted ANCOVAs using the respective psychopathology subscores as co- variates. Accordingly, the forensic group still outperformed the non-forensic patient group with respect to disgust recognition $(\mathrm{F}=$ 8.277; $\mathrm{df}=1 ; p=0.006$ ), and reached higher total scores in the emotion recognition task $(\mathrm{F}=4.960 ; \mathrm{df}=1 ; p=0.030)$ as well as in the recognition of emotions in Caucasian faces $(\mathrm{F}=6.562 ; \mathrm{df}=1 ; p=0.013)$ when the $\operatorname{cog}$ nitive factor on the PANSS was co-varied out. When controlling for "excitement", the

Table 3

Comparison of emotion recognition tasks and gender recognition between forensic and non-forensic patients and healthy controls (Bonferroni-corrected)

MD SE Significance

\begin{tabular}{|c|c|c|c|c|c|}
\hline Happiness* & $\begin{array}{l}\text { Forensic: } 6.3+/-1.9 \\
\text { Non-Forensic: } 5.7+/-2.3\end{array}$ & Controls: $7.4+/-1.3$ & $\operatorname{chi}^{2}=10.60$ & $\mathrm{df}=2$ & $p=0.005$ \\
\hline Surprise* & $\begin{array}{l}\text { Forensic: } 4.7+/-2.7 \\
\text { Non- Forensic: } 4.5+/-2.6\end{array}$ & Controls: $7.2+/-1.3$ & $\operatorname{chi}^{2}=14.45$ & $\mathrm{df}=2$ & $p=0.001$ \\
\hline Sadness & $\begin{array}{l}\text { Forensic: } 2.7+/-1.9 \\
\text { Non-Forensic: } 2.8+/-1.6\end{array}$ & Controls: $4.0+/-2.0$ & $\begin{array}{l}-1.33 \\
-1.23\end{array}$ & $\begin{array}{l}0.522 \\
0.522\end{array}$ & $\begin{array}{l}p=0.038 \\
p=0.062\end{array}$ \\
\hline Fear & $\begin{array}{l}\text { Forensic: } 2.3+/-2.2 \\
\text { Non- Forensic: } 1.6+/-1.5\end{array}$ & Controls: $3.4+/-1.7$ & $\begin{array}{l}-1.05 \\
-1.78\end{array}$ & $\begin{array}{l}0.529 \\
0.529\end{array}$ & $\begin{array}{l}p=0.152 \\
p=0.003\end{array}$ \\
\hline Anger & $\begin{array}{l}\text { Forensic: } 2.9+/-2.2 \\
\text { Non-Forensic: } 3.7+/-2.4\end{array}$ & Controls: $6.1+/-1.6$ & $\begin{array}{l}-3.12 \\
-2.35\end{array}$ & $\begin{array}{l}0.625 \\
0.625\end{array}$ & $\begin{array}{l}p<0.001 \\
p=0.001\end{array}$ \\
\hline Disgust & $\begin{array}{l}\text { Forensic: } 2.8+/-1.9 \\
\text { Non-Forensic: } 1.4+/-1.5\end{array}$ & Controls: $3.5+/-2.0$ & $\begin{array}{l}-0.700 \\
-2.10\end{array}$ & $\begin{array}{l}0.511 \\
0.511\end{array}$ & $\begin{array}{l}p=0.523 \\
p<0.001\end{array}$ \\
\hline Contempt & $\begin{array}{l}\text { Forensic: } 2.4+/-2.3 \\
\text { Non-Forensic: } 2.3+/-2.2\end{array}$ & Controls: $5.0+/-2.5$ & $\begin{array}{l}-2.55 \\
-2.62\end{array}$ & $\begin{array}{l}0.668 \\
0.668\end{array}$ & $\begin{array}{l}p=0.001 \\
p=0.001\end{array}$ \\
\hline $\begin{array}{l}\text { Emotions } \\
\text { sum score }\end{array}$ & $\begin{array}{l}\text { Forensic: } 24.1+/-8.5 \\
\text { Non-Forensic: } 22.0+/-7.8\end{array}$ & Controls: $36.4+/-6.0$ & $\begin{array}{l}-12.28 \\
-14.38\end{array}$ & $\begin{array}{l}2.22 \\
2.22\end{array}$ & $\begin{array}{l}p<0.001 \\
p<0.001\end{array}$ \\
\hline $\begin{array}{l}\text { Emotion } \\
\text { recognition in } \\
\text { Caucasian Faces }\end{array}$ & $\begin{array}{l}\text { Forensic: } 11.9+/-4.4 \\
\text { Non-Forensic: } 10.2+/-3.8\end{array}$ & Controls: $18.2+/-3.4$ & $\begin{array}{l}-6.31 \\
-8.00\end{array}$ & $\begin{array}{l}1.16 \\
1.18\end{array}$ & $\begin{array}{l}p<0.001 \\
p<0.001\end{array}$ \\
\hline $\begin{array}{l}\text { Emotion } \\
\text { recognition in } \\
\text { Japanese Faces }\end{array}$ & $\begin{array}{l}\text { Forensic: } 12.2+/-4.7 \\
\text { Non-Forensic: } 11.3+/-3.9\end{array}$ & Controls: $18.2+/-3.3$ & $\begin{array}{l}-5.991 \\
-6.908\end{array}$ & $\begin{array}{l}1.21 \\
1.22\end{array}$ & $\begin{array}{l}p<0.001 \\
p<0.001\end{array}$ \\
\hline JACBART sex* & $\begin{array}{l}\text { Forensic: } 54.8+/-1.4 \\
\text { Non- Forensic: } 53.9+/-2.9\end{array}$ & Controls: $56.0+/-0$ & $\mathrm{chi}^{2}=4.05$ & $\mathrm{df}=2$ & $p=0.132$ \\
\hline
\end{tabular}

$\mathrm{MD}=$ mean difference; $\mathrm{SE}=$ standard error.

Items marked by an asterisk* were compared using non-parametric statistics. 
forensic group outperformed the non-forensic group regarding happiness $(\mathrm{F}=4.417 ; \mathrm{df}$ $=1 ; p=0.040)$, fear $(\mathrm{F}=5.401 ; \mathrm{df}=1 ; p=$ $0.024)$, disgust $(\mathrm{F}=7.032 ; \mathrm{df}=1 ; p=0.010)$, total emotion recognition score $(\mathrm{F}=4.576$; $\mathrm{df}$ $=1 ; p=0.037)$ and emotion recognition in Caucasian faces $(\mathrm{F}=4.654$; $\mathrm{df}=1 ; p=$ 0.035). When co-varying out the depression and anxiety component of the PANSS, the difference between the two patient groups with respect to disgust recognition remained significant $(\mathrm{F}=7.978 ; \mathrm{df}=1 ; p=0.007)$ but no other difference was obtained. No difference in emotion recognition - except disgust - emerged when controlling for age at onset of the schizophrenia (all $p=>0.05$ ).

\section{Neuropsychological performance}

As expected, both patient groups performed more poorly than controls on both measures of executive functioning, but did not differ between each other. They both made more perseverative errors in the WCST than controls (forensic vs. controls: MannWhitney-U =75.000; $\mathrm{Z}=-4.400 p=<0.001$; non-forensic vs. controls: Mann-Whitney-U $=117.000 ; Z=-3.465 ; p=0.001$; forensic vs. non-forensic: Mann-Whitney-U = 335.500; $\mathrm{Z}=-1.525 ; p=0.127$ ), and performed more poorly on the executive planning task. No difference emerged between the clinical groups regarding executive planning skills as measured using the Zoo Map Test $(\mathrm{t}=$ 0.620 ; df $=58 ; p=0.538$ ). For more details see Table 1.

\section{Correlations within the two patient groups}

Parametric correlation analyses in the forensic group revealed that emotion recognition (total score) correlated inversely with the amount of antipsychotic medication $(r=$
$-0.567, p=0.001)$. In addition SpearmanRho correlations revealed an inverse relationship of emotion recognition with the cognitive component (rho $=-0.456, p=0.013$ ) and with the positive component of the PANSS (rho $=-0.387, p=0.038$ ) in the forensic patient group, but with none of the other PANSS components (all other $p>$ $0.05)$. No correlations of emotion recognition (total score) emerged with any one of the executive functioning tasks (i.e., WCST perseverative errors, Zoo Map Test (all $p>$ 0.05 ), or with any of the demographic variables (i.e., age at onset of the schizophrenia, duration of illness, education (all $p>0.05$ ) among forensic patients.

Similar to the forensic group, in the nonforensic patient group emotion recognition correlated inversely with the cognitive component of the PANSS (rho $=-0.407, p=$ 0.029). There were no correlations between the non-forensic patients' global performance on the emotion recognition tasks with any of the other subscales of the PANSS (all $p>0.05$ ), with any of the executive functioning tasks (i.e. WCST perseverative errors, Zoo Map Test (all $p>0.05$ )), or with any of the demographic variables (all $p>0.05$ ). In contrast to the forensic patient group, no relationship emerged between emotion recognition tasks and chlorpromazine equivalents in the non-forensic group $(p>0.05)$.

\section{Hierarchical regression analyses}

Due to several confounding factors such as sex differences between the groups, differences in education and executive functioning, we performed a hierarchical regression analysis with "emotion recognition" as the dependent variable. To examine the contribution of each variable to the overall variance, we entered "sex", "education", the number of perseverative errors in the WCST, the Zoo 
Map score, the excitement component of the PANSS, the cognitive component of the PANSS and "group" (forensic, non-forensic, control) one at a time as independent variables in the equation. Preliminary analyses were conducted to ensure no violation of the assumptions of normality, linearity, multicollinearity. All steps of the hierarchical model were significant. In the final step, only the cognitive component of the PANSS ( $\mathrm{B}=-0.355, p=0.014)$ and diagnostic group $(\mathrm{B}=0.274, p=0.031)$ contributed significantly, where diagnostic group explained an additional $4 \%$ of the variance predicting emotion recognition, after controlling for all confounding factors $\left(R_{\text {squared change }}=0.038, F_{\text {change }}(1\right.$, $67)=4.852, p=0.031)$, whereas all other factors became non-significant (Table 4).

Table 4

Hierarchical regression model predicting emotion recognition

\begin{tabular}{|c|c|c|c|c|}
\hline Model & & B & $\mathrm{t}$ & Sig. \\
\hline Step $1^{\mathrm{a}}$ & Sex & -0.290 & -2.684 & 0.009 \\
\hline & Education & 0.311 & 2.873 & 0.005 \\
\hline Step $2^{\mathrm{b}}$ & Sex & -0.243 & -2.206 & 0.031 \\
\hline & Education & 0.264 & 2.397 & 0.019 \\
\hline & Perseverative errors in the WCST & -0.191 & -1.692 & 0.095 \\
\hline Step $3^{c}$ & Sex & -0.228 & -2.179 & 0.033 \\
\hline & Education & 0.292 & 2.776 & 0.007 \\
\hline & Perseverative errors in the WCST & -0.110 & -1.000 & 0.321 \\
\hline & Executive planning (ZMT) & 0.311 & 2.961 & 0.004 \\
\hline Step $4^{\mathrm{d}}$ & Sex & -0.129 & -1.180 & 0.242 \\
\hline & Education & 0.237 & 2.274 & 0.026 \\
\hline & Perseverative errors in the WCST & -0.038 & -0.346 & 0.730 \\
\hline & Executive planning (ZMT) & 0.268 & 2.603 & 0.011 \\
\hline & Excitement factor (PANSS) & -0.286 & -2.416 & 0.018 \\
\hline Step $5^{\mathrm{e}}$ & Sex & -0.108 & -1.059 & 0.293 \\
\hline & Education & 0.204 & 2.098 & 0.040 \\
\hline & Perseverative errors in the WCST & -0.014 & -0.137 & 0.892 \\
\hline & Executive planning (ZMT) & 0.157 & 1.548 & 0.126 \\
\hline & Excitement factor (PANSS) & -0.017 & -0.126 & 0.900 \\
\hline & Cognitive factor (PANSS) & -0.462 & -3.412 & 0.001 \\
\hline Step $6^{\mathrm{f}}$ & Sex & -0.087 & -0.869 & 0.388 \\
\hline & Education & 0.136 & 1.369 & 0.176 \\
\hline & Perseverative errors in the WCST & -0.035 & -0.349 & 0.728 \\
\hline & Executive planning (ZMT) & 0.110 & 1.092 & 0.279 \\
\hline & Excitement factor (PANSS) & 0.035 & 0.263 & 0.793 \\
\hline & Cognitive factor (PANSS) & -0.355 & -2.533 & 0.014 \\
\hline & Group (healthy, forensic, non-forensic) & 0.274 & 2.203 & 0.031 \\
\hline
\end{tabular}

\footnotetext{
${ }^{\text {an }}{ }^{2}=0.165, \mathrm{df}=2,72, \mathrm{p}=0.002$.

${ }^{\mathrm{b}} \mathrm{R}^{2}=0.197, \mathrm{df}=1,71, \mathrm{p}=0.001$.

${ }^{\mathrm{c}} \mathrm{R}^{2}=0.286, \mathrm{df}=1,70, \mathrm{p}<0.001$.

${ }^{\mathrm{d}} \mathrm{R}^{2}=0.342, \mathrm{df}=1,69, \mathrm{p}<0.001$.

${ }^{\mathrm{e}} \mathrm{R}^{2}=0.438, \mathrm{df}=1,68, \mathrm{p}<0.001$.

${ }^{\mathrm{f}} \mathrm{R}^{2}=0.476, \mathrm{df}=1,67, \mathrm{p}<0.001$.
} 
In a second hierarchical regression model, we used the same approach to determine the predictors of disgust recognition. Since the number of perseverative errors was not a predictor of emotion recognition in any one of the steps, we excluded this variable from the list of independent variables. In contrast to the first hierarchical regression analysis, only the last step of the model approached significance $(p=0.06)$, whereas the former steps were not significant. However, after controlling for all confounding factors "group" became the only significant factor predicting disgust recognition differences between the groups, explaining $12 \%$ of the variance $\left(R^{2}\right.$ change $=0.123, F_{\text {change }}(1,70)=10.167, p=$ 0.031 ) (Table 5). This suggests that the group differences in emotion recognition, including disgust, were largely independent of the confounding factors.

Table 5

Hierarchical regression model predicting the recognition of disgust

\begin{tabular}{|c|c|c|c|c|}
\hline Model & & B & $\mathrm{t}$ & Sig. \\
\hline Step $1^{\mathrm{a}}$ & Sex & -0.001 & -0.008 & 0.993 \\
\hline & Education & 0.154 & 1.335 & 0.186 \\
\hline Step $2^{b}$ & Sex & 0.005 & 0.046 & 0.963 \\
\hline & Education & 0.156 & 1.350 & 0.181 \\
\hline & Executive planning (ZMT) & 0.061 & 0.522 & 0.603 \\
\hline Step $3^{c}$ & Sex & 0.004 & 0.032 & 0.975 \\
\hline & Education & 0.157 & 1.308 & 0.195 \\
\hline & Executive planning (ZMT) & 0.061 & 0.510 & 0.611 \\
\hline & Excitement factor (PANSS) & 0.003 & 0.026 & 0.980 \\
\hline Step $4^{\mathrm{d}}$ & Sex & 0.006 & 0.050 & 0.960 \\
\hline & Education & 0.153 & 1.263 & 0.211 \\
\hline & Executive planning (ZMT) & 0.044 & 0.338 & 0.736 \\
\hline & Excitement factor (PANSS) & 0.045 & 0.266 & 0.791 \\
\hline & Cognitive factor (PANSS) & -0.069 & -0.395 & 0.694 \\
\hline Step $5^{\mathrm{e}}$ & Sex & 0.031 & 0.256 & 0.799 \\
\hline & Education & 0.053 & 0.445 & 0.658 \\
\hline & Executive planning (ZMT) & -0.047 & -0.377 & 0.707 \\
\hline & Excitement factor (PANSS) & 0.125 & 0.770 & 0.444 \\
\hline & Cognitive factor (PANSS) & 0.125 & 0.715 & 0.477 \\
\hline & Group (healthy, forensic, non-forensic) & 0.487 & 3.189 & 0.002 \\
\hline
\end{tabular}

${ }^{\mathrm{a}} \mathrm{R}^{2}=0.024, \mathrm{df}=2,74, \mathrm{p}=0.414$
$\mathrm{C}^{\mathrm{b}}=0.027, \mathrm{df}=1,73, \mathrm{p}=0.567$
${ }^{\mathrm{c}} \mathrm{R}^{2}=0.027, \mathrm{df}=1,72, \mathrm{p}=0.733$
${ }^{\mathrm{d}} \mathrm{R}^{2}=0.029, \mathrm{df}=1,71, \mathrm{p}=0.827$
${ }^{\mathrm{e}} \mathrm{R}^{2}=0.152, \mathrm{df}=1,70, \mathrm{p}=0.064$ 


\section{Discussion}

The present study sought to explore differences in the ability to recognize facial expressions of emotions between forensic and non-forensic schizophrenia patients. Similar to previous studies (for a review, see 6), both schizophrenia patient groups performed significantly more poorly on a novel emotion recognition $\operatorname{task}^{22}$ than healthy controls. The control group outperformed the nonforensic patients on all seven basic emotions as well as total emotion recognition score. Unexpectedly, however, the forensic group scored equally well as the control group in the recognition of disgust, whereas the control group outperformed the forensic patients on all other emotions. Accordingly, the forensic group performed significantly better than the non-forensic patient group with regard to disgust recognition, even when all other clinical and demographic parameters distinguishing the two clinical groups were co-varied out. In addition, hierarchical regression analyses demonstrated that the differences between the groups as regards emotion recognition, specifically disgust recognition, were independent of sex, education, executive functioning, and notably, largely independent of psychopathology.

Earlier studies in schizophrenia discovered specific impairments of schizophrenia patients with respect to the recognition of disgust and fear ${ }^{12}$. In contrast, Harmer et al. ${ }^{27}$ found enhanced recognition of disgust in facial expressions in euthymic patients with bipolar disorder ${ }^{27}$, what they interpreted as a result of decreased self-esteem because of the illness. Nevertheless, Hayward et al. ${ }^{28}$ demonstrated an increased recognition of disgust in remitted patients with depres$\operatorname{sion}^{28}$. A similar argument was put forth by Martin et al. ${ }^{29}$ who found superior recognition of disgust in subjects with current opiate abuse ${ }^{29}$, which was interpreted as response to stigmatizing experiences including repeated exposure to facial expressions of disgust that may have caused hypersensitivity with regard to this expression. As an alternative explanation, the authors suggested that a negative self-concept may have heightened the sensitivity towards disgust ${ }^{29}$. Interestingly, a recent study by Hansen et al. ${ }^{30}$ revealed associations of various subscores of the Hare Psychopathy Checklist-Revised $^{31}$ with the ability to recognize disgust ${ }^{30}$. In particular, impulsivity and antisocial behavior were positively correlated with the ability of psychopathic individuals to recognize disgust, whereas a negative relationship was found between an arrogant interpersonal style and the detection of disgust in female faces ${ }^{30}$. This may apply to the forensic patient group in the present study.

Consistent with this finding, forensic patients showed significantly more excitement and cognitive symptoms on the PANSS compared with non-forensic schizophrenia patients. When co-varying out the cognitive component (comprising conceptual disorganization, disorientation, and difficulty in abstract thinking, mannerisms and posturing as well as poor attention), the forensic patients outperformed the non-forensic schizophrenic patients on the total score of the emotion recognition task and recognition of emotions in Caucasian faces. More importantly, when controlling for the excitement component (comprising excitement, poor impulse control, hostility and tension) the expressions of happiness and fear were recognized better by forensic patients than non-forensic patients in addition to the superior disgust recognition of the former.

Interestingly, we found an inverse correlation between emotion recognition ability and antipsychotic medication in the forensic patient group but not in the non-forensic 
group. Both groups did not differ regarding the amount of antipsychotics as estimated in CPZ equivalents. Notably, forensic patients received more first-generation antipsychotics than the non-forensic patient group, the majority of who were treated with secondgeneration antipsychotics. It has repeatedly been demonstrated that patients receiving first-generation antipsychotic medication are impaired in comparison to patients treated with second-generation antipsychotics with respect to their emotion recognition ability ${ }^{32,33}$. However, the fact that the forensic group performed better than the nonforensic patient group on emotion recognition tasks rather supports the interpretation that medication either did not play a decisive role in our sample, or that the difference in favor of the forensic patients would have been even larger, had they received second-generation antipsychotics like the non-forensic patients.

Similar to previous studies ${ }^{34}$, our mostly Caucasian participants recognized emotional expressions in faces equally well irrespective of poser ethnicity. Notably, we did not obtain any difference regarding the gender recognition tasks between the three groups, which is in line with the findings of Bediou and colleagues ${ }^{1,4}$. This lends support to the assumption that schizophrenia patients have a specific deficit in facial emotion recognition rather than a more global face processing deficit. In the gender recognition there were only two options to choose the correct answer from, whereas in the emotion recognition task seven alternatives were presented, which arguably renders the gender recognition task easier than the emotion recognition task. However, the presentation time of $200 \mathrm{~ms}$ of each face put equal pressure on subjects in both conditions, which makes at least attention deficits unlikely to be the cause for the selective emotion recognition deficit in patients.
This study has several limitations. Firstly, we were unable to obtain PCL-R scores for our forensic sample, such that the possible association of psychopathic dimensions with disgust recognition in our forensic sample remains to some extent speculative, although previous studies have shown high rates of comorbidity between schizophrenia and psychopathy in forensic populations ${ }^{20}$. However, the usefulness of the PCL-R in schizophrenia has been a matter of some controversy ${ }^{35}$, since in one older study a large number of patients $(50 \%)$ with schizophrenia was incorrectly diagnosed with comorbid psychopathy ${ }^{36}$. Secondly, the limited sample size precluded a meaningful subtyping of schizophrenia. This could be relevant, however, because patients with paranoid schizophrenia have been shown to perform better than non-paranoid patients on emotion recognition tasks ${ }^{5}$. It is conceivable that a paranoid subgroup of patients was overrepresented in our forensic sample, which might account for their preserved ability to identify disgust. Thirdly, both clinical groups were not ideally matched for sex and antipsychotic treatment. We tried to control for these confounding factors in a hierarchical regression analysis and found that they did not contribute to the differences in emotion recognition between the groups. However, future studies should take such differences into consideration. Fourthly, it would have been ideal to include a forensic and nonforensic control group, to further substantiate the hypothesis that differences in disgust recognition were related to a history of forensically relevant behavior. Finally, the JACBART was not validated in a German sample, so the present findings need to be regarded as explorative.

Novel approaches using specific training modules for improving social cognition in schizophrenia patients have proven successful, especially in forensic patients. The Social 
Cognition and Interaction (SCIT) program, for example, reduced hostility in forensic patients after a 16-week training of social cognition skills as well as it did increase cognitive flexibility and reduced need for closure ${ }^{37}$.

In summary, this finding could tentatively be interpreted to suggest that there are differences in emotion recognition between forensic and non-forensic patients within the spectrum of schizophrenia, a finding that could be relevant for the diagnostic evaluation of offenses associated with mental illness.

\section{References}

1. Bediou B, Krolak-Salmon P, Saoud M, Henaff MA, Burt M, Dalery J, et al. Facial expression and sex recognition in schizophrenia and depression. Can J Psychiatr 2005; 50(9): 525-533.

2. Streit M, Wölwer W, Gaebel W. Facial-affect recognition and visual scanning behaviour in the course of schizophrenia. Schizophr Res 1997; 24(3): 311-317.

3. Ekman P. Facial Expressions. In: Dalgleish T, Power M, eds. Handbook of Cognition and Emotion. New York: John Wiley and Sons Ltd; 1999.

4. Bediou B, Asri F, Brunelin J, Krolak-Salmon P, D'Amato T, Saoud M, et al. Emotion recognition and genetic vulnerability to schizophrenia. Br J Psychiatry 2007; 191: 126-130.

5. Lewis SF, Garver DL. Treatment and diagnostic subtype in facial affect recognition in schizophrenia. J Psychiatr Res 1995; 29(1): 5-11.

6. Mandal MK, Pandey R, Prasad AB. Facial expressions of emotions and schizophrenia: a review. Schizophr Bull 1998; 24(3): 399-412.

7. Sachs G, Steger-Wuchse D, Kryspin-Exner I, Gur $\mathrm{RC}$, Katschnig H. Facial recognition deficits and cognition in schizophrenia. Schizophr Res 2004; 68(1): 27-35.

8. Hall J, Harris JM, Sprengelmeyer R, Sprengelmeyer A, Young AW, Santos IM, et al. Social cognition and face processing in schizophrenia. Br J Psychiatry 2004; 185 : 169-170.

9. Mueser KT, Doonan R, Penn DL, Blanchard JJ, Bellack AS, Nishith $\mathrm{P}$, et al. Emotion recognition and social competence in chronic schizophrenia. J Abnorm Psychol 1996; 105(2): 271-275.

10. Schneider F, Gur RC, Koch K, Backes V, Amunts K, Shah NJ, et al. Impairment in the specificity of emotion processing in schizophrenia. Am J Psychiatry 2006; 163(3): 442-447.

11. Edwards J, Pattison PE, Jackson HJ, Wales RJ. Facial affect and affective prosody recognition in first-episode schizophrenia. Schizophr Res 2001; 48(2-3): 235-253.

12. Kohler CG, Turner TH, Bilker WB, Brensinger CM, Siegel SJ, Kanes SJ, et al. Facial emotion recognition in schizophrenia: intensity effects and error pattern. Am J Psychiatry 2003; 160(10): 1768-1774.

13. Johnston PJ, Devir H, Karayanidis F. Facial emotion processing in schizophrenia: no evidence for a deficit specific to negative emotions in a differential deficit design. Psychiatry Res 2006; 143(1): 51-61.

14. Wölwer W, Streit M, Polzer U, Gaebel W. Facial affect recognition in the course of schizophrenia. Eur Arch Psychiatry Clin Neurosci 1996; 246(3): 165-170.

15. Poole JH, Tobias FC, Vinogradov S. The functional relevance of affect recognition errors in schizophrenia. J Int Neuropsychol Soc. 2000; 6(6): 649-658.

16. Kerr SL, Neale JM. Emotion perception in schizophrenia: specific deficit or further evidence of generalized poor performance? J Abnorm Psychol 1993; 102(2): 312318.

17. Kohler CG, Bilker W, Hagendoorn M, Gur RE, Gur RC. Emotion recognition deficit in schizophrenia: association with symptomatology and cognition. Biol Psychiatry 2000; 48(2): 127-136.

18. Hoaken PN, AllabyDB, Earle J. Executive cognitive functioning and the recognition of facial expressions of emotion in incarcerated violent offenders, non-violent offenders, and controls. Aggress Behav 2007; 33(5): 412-421.

19. Weiss EM, Kohler CG, Nolan KA, Czobor P, Volavka $\mathrm{J}$, Platt MM, et al. The relationship between history of violent and criminal behavior and recognition of facial expression of emotions in men with schizophrenia and schizoaffective disorder. Aggress Behav 2006; 32(3): 187-194.

20. Fullam R, Dolan M. Emotional information processing in violent patients with schizophrenia: association with psychopathy and symptomatology. Psychiatry Res 2006; 141(1): 29-37.

21. World Health Organization. The ICD-10 classification of mental and behavioural disorders: Diagnostic criteria for research. Geneva: World Health Organization; 1993.

22. Matsumoto D, LeRoux J, Wilson-Cohn C, Raroque J, Kooken K, Ekman P, et al. A New Test to Measure Emotion 
Recognition Ability: Matsumoto and Ekman's Japanese and Caucasian Brief Affect Recognition Test (JACBART). J Nonverb Behav 2000; 24(3): 179-209.

23. Nelson HE. A modified card sorting test sensitive to frontal lobe defects. Cortex 1976; 12(4): 313-324.

24. Wilson BA, Alderman N, Burgess P, Emslie H, Evans JJ. Behavioural Assessment of the Dysexecutive Syndrome (BADS). Bury, St. Edmunds: Thames Valley Test; 1996.

25. Kay SR, Opler LA, Lindenmayer JP. The Positive and Negative Syndrome Scale (PANSS): rationale and standardisation. Br J Psychiatry 1989; Suppl(7): 59-67.

26. Lindenmayer JP, Bernstein-Hyman R, Grochowski S. A new five factor model of schizophrenia. Psychiatr Q 1994; 65(4): 299-322.

27. Harmer CJ, Grayson L, Goodwin GM. Enhanced recognition of disgust in bipolar illness. Biol Psychiatry 2002; 51(4): 298-304.

28. Hayward G, Goodwin GM, Cowen PJ, Harmer CJ. Low-dose tryptophan depletion in recovered depressed patients induces changes in cognitive processing without depressive symptoms. Biol Psychiatry 2005; 57(5): 517-524.

29. Martin L, Clair J, Davis P, O’Ryan D, Hoshi R, Curran HV. Enhanced recognition of facial expressions of disgust in opiate users receiving maintenance treatment. Addiction 2006; 101(11): 1598-1605.

30. Hansen AL, Johnsen BH, Hart S, Waage L, Thayer JF. Brief communication: psychopathy and recognition of facial expressions of emotion. J Pers Disord 2008; 22(6): 639-644.

31. Hare RD. The Hare psychopathy checklist-revised. Toronto: Multi-Health Systems, Inc; 1991.
32. Kee KS, Kern RS, Marshall BDJr, Green MF. Risperidone versus haloperidol for perception of emotion in treatment-resistant schizophrenia: preliminary findings. Schizophr Res 1998; 31(2-3): 159-165.

33. Williams LM, Loughland CM, Green MJ, Harris AW, Gordon E. Emotion perception in schizophrenia: an eye movement study comparing the effectiveness of risperidone vs. haloperidol. Psychiatry Res 2003; 120(1): 13-27.

34. Pinkham AE, Sasson NJ, Calkins ME, Richard J, Hughett P, Gur RE, et al. The other-race effect in face processing among African American and Caucasian individuals with schizophrenia. Am J Psychiatry 2008; 165(5): 639-645.

35. Raine A. Psychopathy, schizoid personality and borderline/ schizotypal personality disorders. Pers Individ Diff 1986; 7(4): 493-501.

36. Howard R, Bailey R, Newman A. A preliminary study of Hare's "Research Scale for the Assessment of Psychopathy" in mentally-abnormal offenders. Pers Individ Diff 194; 5: 389-396.

37. Combs DR, Adams SD, Penn DL, Roberts D, Tiegreen J, Stem P. Social Cognition and Interaction Training (SCIT) for inpatients with schizophrenia spectrum disorders: Preliminary findings. Schizophr Res 2007; 91: 122-126.

Author for correspondence:

Prof. Dr. Martin Brüne

Phone: +49-234-5077-1130

Fax: +49-234-5077-1329

E-mail: martin.bruene@rub.de 